\title{
PENYULUHAN PENTINGNYA IMUNISASI DAN PENATALAKSANAAN DEMAM PADA ANAK PASCA IMUNISASI DI PUSKESMAS SULAMADAHA
}

\author{
Marhaeni Hasan', Fera The ${ }^{2}$ \\ ${ }^{1,2}$ Program Studi Pendidikan Dokter, Fakultas Kedokteran, Universitas Khairun, Ternate
}

email fera_the@yahoo.com

\begin{abstract}
ABSTRAK
Pengabdian telah dilaksanakan di Poskesdes Tobololo yang merupakan daerah pelayanan Puskesmas Sulamadaha, Kota Ternate, Maluku Utara. Pelaksanaan kegiatan dilaksanakan pada Selasa tanggal 17 September 2019. Tujuan dari kegiatan ini adalah meningkatkan pengetahuan kesehatan anak kepada orangtua melalui penyuluhan pentingnya imunisasi dan penatalaksanaan demam pada anak pasca imunisasi. Masyarakat yang hadir adalah peserta dan diberikan penyuluhan mengenai imunisasi dan penatalaksanaannya ketika demam, sehingga masyarakat menyadari pentingnya imunisasi dan dapat melakukan penanganan awal ketika anak demam pasca imunisasi.
\end{abstract}

Kata Kunci: Imunisasi, Demam, Puskesmas Sulamadaha

\begin{abstract}
Service has been carried out at the Tobololo Poskesdes which is a service area of the Sulamadaha Community Health Center, Ternate City, North Maluku. The activity will be held on Tuesday 17 September 2019. The purpose of this activity is to increase children's health knowledge to parents through counseling the importance of immunization and management of fever in children after immunization. The people present were 78 participants and were given counseling about immunization and its management when there was a fever, so the community was aware of the importance of immunization and was able to do initial treatment when the child had a fever after immunization.
\end{abstract}

Keywords: immunization, fever, Sulamadaha Community Health Center.

\section{PENDAHULUAN}

Kegiatan Imunisasi merupakan upaya yang paling cost effective dalam menurunkan angka kesakitan dan kematian akibat penyakit yang dapat dicegah dengan imunisasi (PD3I) yang diharapkan dapat menurunkan angka kematian bayi dan balita (Kemenkes, 2014).

Tujuan umum imunisasi menurut Kemenkes RI adalah untuk menurunkan angka kesakitan, kematian, dan kecacatan akibat penyakit yang dapat dicegah dengan imunisasi (PD3I). Beberapa tahun 
terakhir ini di Indonesia terjadi penurunan angka kematian bayi dan balita. Laporan dari Kementerian Kesehatan RI pada tahun 2015 menunjukkan angka kematian bayi dan balita berturut-turut adalah 22,23 per 1000 kelahiran hidup dan 26,2 per 1000 kelahiran hidup.

Penurunan angka kematian bayi dan balita tentu saja dari usaha pemerintah dalam menciptakan program pencegahan yang telah mengurangi kebutuhan kuratif dan rehabilitatif. Salah satu usaha pencegahan yang berhasil adalah program imunisasi (Ranuh, 2014).

Dalam hal menunjang sistem kesehatan nasional, program imunisasi sangat efektif dan efisien apabila diberikan dalam cakupan yang luas secara nasional. Peningkatan pertumbuhan ekonomi suatu negara tentunya akan lebih baik bila masyarakatnya lebih sehat sehingga anggaran untuk kuratif/pengobatan dapat dialihkan pada program lain yang membutuhkan. Investasi dalam kesehatan untuk kesejahteraan dan peningkatan kualitas anak di masa depan (Ranuh, 2014).

KIPI adalah kejadian medik yang berhubungan dengan imunisasi baik berupa reaksi vaksin, reaksi suntikan, efek farmakologis, kesalahan prosedur, koinsiden atau hubungan kausal yang tidak dapat ditentukan. KIPI serius merupakan kejadian medis setelah imunisasi yang tak diinginkan yang menyebabkan rawat inap atau perpanjangan rawat inap, kecacatan yang menetap atau signifikan dan kematian, serta menimbulkan keresahan di masyarakat (Kemenkes, 2014).

Pencegahan reaksi KIPI akibat reaksi suntikan bisa dilakukan dengan menerapkan teknik penyuntikan yang benar, membuat suasana tempat penyuntikan yang tenang dan mengatasi rasa takut pada anak. Pencegahan terhadap reaksi vaksin, diantaranya perhatikan indikasi kontra, tidak memberikan vaksin hidup kepada anak defisiensi imunitas, ajari orangtua menangani reaksi vaksin yang ringan dan anjurkan untuk segera kembali apabila ada reaksi yang mencemaskan (paracetamol dapat diberikan 4x sehari untuk mengurangi gejala demam dan rasa nyeri), kenali dan atasi reaksi anafilaksis, siapkan rujukan ke rumah sakit dengan fasilitas lengkap (Akib, 2011).

Sulamadaha adalah kelurahan yang terlateak di kecamatan Pulau Ternate Provinsi Maluku Utara dengan daerah pemukiman penduduk umumnya membentang di sepanjang garis pantai. Mata pencaharian masyarakat Kelurahan Sulamadaha sebagian besar bertani dan nelayan serta tingkat pendidikan masih sangat rendah di mana kebanyakan masyarakat di Sulamadaha tidak tamat/belum sekolah dan tamat SLTA.

Dari uraian di atas, dapat dilihat bahwa diperlukan adanya upaya edukasi melalui penyuluhan mengenai pentingnya imunisasi dan cara penatalaksanaan demam yang merupakan KIPI yang paling 
umum terjadi agar derajat kesehatan masyarakat di Kelurahan Sulamadaha Pulau Ternate dapat lebih baik lagi.

\section{METODE}

Pelaksanaan kegiatan pada hari Selasa tanggal 17 September 2019 pukul 08.00 WIT sampai selesai. Kegiatan dilaksanakan di Poskesdes Tobololo yang merupakan daerah pelayanan Puskesmas Sulamadaha. Kegiatan yang diberikan berupa penyuluhan tentang penyuluhan pentingnya imunisasi dan penatalaksanaan demam pada anak pasca imunisasi. Kegiatan ini dilaksanakan dengan tujuan meningkatkan pengetahuan kesehatan anak kepada orang tua melalui penyuluhan pentingnya imunisasi dan penatalaksanaan demam pada anak pasca imunisasi serta meningkatkan jiwa sosial dari civitas akademik Fakultas Kedokteran Universitas Khairun Ternate.

\section{PEMBAHASAN}

Pelaksanaan kegiatan pada hari Selasa tanggal 17 September 2019 pukul 08.00 WIT sampai selesai. Kegiatan dilaksanakan di Poskesdes Tobololo yang merupakan daerah pelayanan Puskesmas Sulamadaha. Kegiatannya meliputi penyuluhan mengenai pentingnya imunisasi dan penatalaksanaan demam pada anak post imunisasi. Selain dilakukan penyuluhan, masyarakat juga dibagikan leaflet yang berisikan tentang informasi mengenai pentingnya imunisasi dan penatalaksaaan demam. Masyarakat yang hadir juga membawa anak mereka dan dilakukan diskusi maupun konsultasi dengan pemateri yaitu dokter spesialis anak mengenai imunisasi dan permasalahan kesehatan yang dialami anak mereka. Kegiatan ini dihadiri oleh 78 peserta yang terdiri dari ibu-ibu dan calon ibu

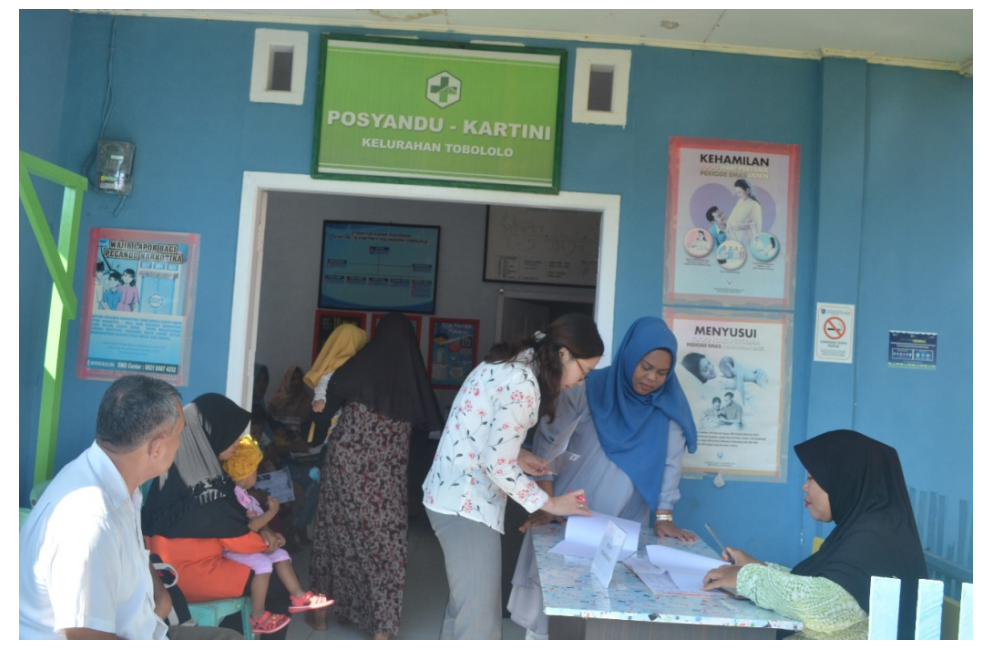




\section{Gambar 1. Pembagian brosur pada masyarakat}

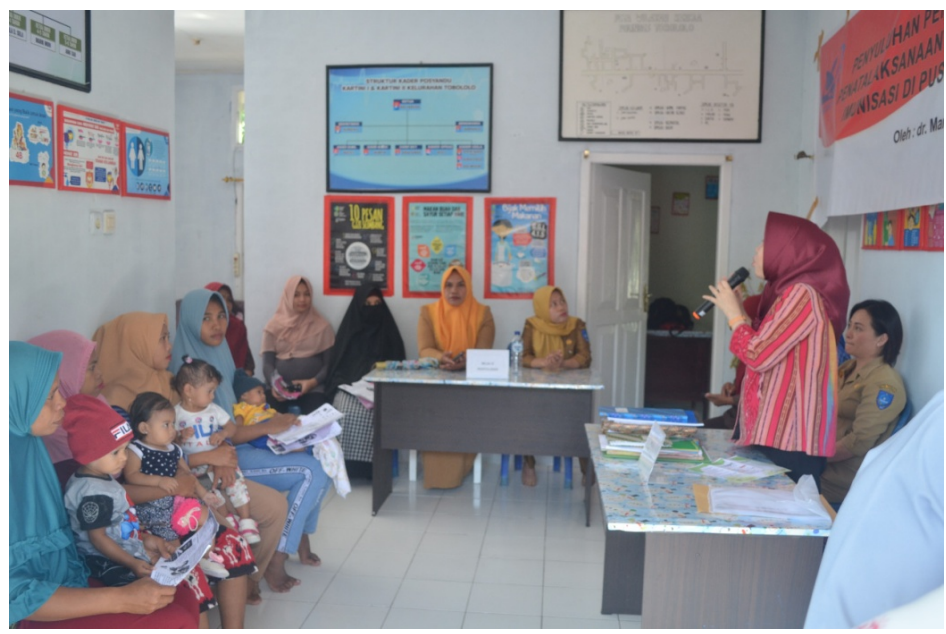

Gambar 2. Penyuluhan mengenai imunisasi

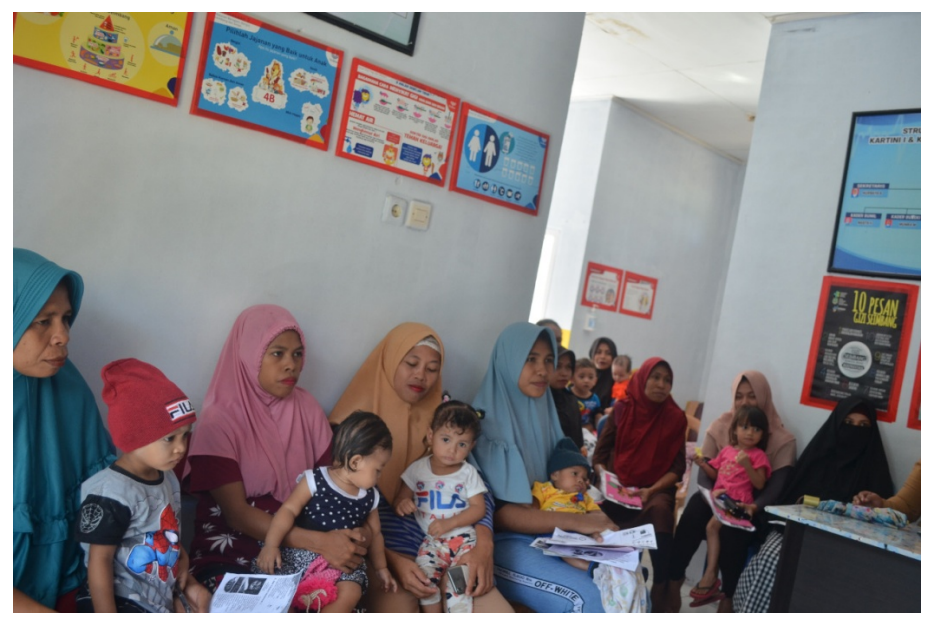

Gambar 3. Peserta Penyuluhan

\section{SIMPULAN}

Hasil Penyuluhan mengenai pentingnya imunisasi dan penatalaksanaan demam pada anak post imunisasi memberikan pengetahuan kepada orang tua agar mendapatkan imunisasi lengkap dan mengetahui mengenai penanganan awal ketika anak demam. Sehingga anak-anak dapat terhindar dari penyakit berbahaya yang dapat dicegah dengan imunisasi. 


\section{UCAPAN TERIMAKASIH}

Ucapan terima kasih kami sampaikan kepada Universitas Khairun yang telah membiayai kegiatan ini melalui Hibah Pengabdian Masyarakat pendanaan tahun 2018. Penulis juga mengucapkan terima kasih kepada pihak yang membantu kegiatan ini di lapangan.

\section{DAFTAR PUSTAKA}

Akib, P.A., Purwanti, A. 2011. Kejadian Ikutan Pasca Imunisasi (KIPI) Adverse Events following Immunization (AEFI) dalam Pedoman Imunisasi di Indonesia. IDAI, Jakarta.

Kemenkes RI. 2014. Buku Ajar Imunisasi. Pusat Pelatihan dan Pendidikan Tenaga Kesehatan, Jakarta.

Ranuh, I.G.N. 2014. Pedoman Imunisasi di Indonesia. Badan Penerbit Ikatan Dokter Anak Indonesia, Jakarta. 